\title{
Os números dos mundos
}

\section{The numbers of the worlds}

ISABEL CAFEZEIRO

Universidade Federal Fluminense | UFF

RICARDO KUBRUSLY

Universidade Federal do Rio de Janeiro | UFRJ

EDWALDO CAFEZEIRO

Universidade Federal do Rio de Janeiro | UFRJ

Para muita gente é difícil meter na cabeça que balé e samba, feijoada e xadrez, sejam modalidades [...] de expressão cultural. ${ }^{1}$

Darcy Ribeiro, 1986, Revista do Brasil

RESUMO Observando afinidades entre matemática, discurso e outras manifestações da nossa cultura, buscamos evidenciar que: (1) As disciplinas, por si só, não dão conta de cumprir com questões que elas próprias se propõem. Para fazerem isso, demandam a participação de outros conhecimentos, no escopo de outras disciplinas. Sendo assim, não há entidades "puras", plenamente concebidas dentro de uma disciplina. (2) Modos de pensamento se configuram a partir da conjuntura histórica, no fluxo dos acontecimentos de um tempo em um lugar. Destes modos de pensamento se derivam os conceitos que são enunciados nas diferentes disciplinas. Uma vez expressos no jargão disciplinar, estes não deixam transparecer o seu caráter situado, independentes das fronteiras disciplinares. A partir destas constatações propomos uma leitura desdisciplinar daquilo que seria dito matemático.

Palavras-chave Fronteiras disciplinares - modos de pensamento situados - matemática e cultura - leitura desdisciplinar.

ABSTRACT Building upon affinities between mathematics, discourse, and other manifestations of our culture, we try to show that: (1) Disciplines, by themselves, are not able to tackle the questions they set to themselves. In order to do so, they demand the collaboration of other knowledge bodies, which are in the scope of different disciplines. Thus, there are no "pure" entities, wholly conceived inside a discipline. (2) Modes of thought configure themselves from historical conjunctures, in the flux of events of a particular time and place. The concepts enunciated in different disciplines spring from these modes of thought. Once they are expressed in disciplinary jargon, such concepts do not reveal their situated character, independent of disciplinary boundaries. From these insights we suggest an "un-disciplinary" reading of what is called mathematical.

Keywords Disciplinary boundaries - situated modes of thought-mathematics and culture-un-disciplinary reading. 


\title{
No rodar da nora, a matemática dos mundos
}

\author{
Esta seção propõe repensar a matemática, bem como qualquer outra \\ forma de conhecimento, a partir das coisas do nosso mundo, conjuntura \\ histórica, fluxo dos acontecimentos de um tempo em um lugar.
}

Em Portugal se chama "nora" e no Brasil "roda d'água". É uma roda, movimentada por tração animal. Em torno da roda há recipientes que, no giro, mergulham numa cisterna cheia d’água, e sobem cheios. Lá em cima, já no percurso de descida, eles deixam a água derramar-se em um cano, que então, a transfere para um outro lugar. Saramago² diz: “(...) porque o mundo é ele uma nora e são os homens que, andando em cima dele, o puxam e fazem andar. Mesmo já cá não estando Sebastiana Maria de Jesus para ajudar com as suas revelações, é fácil ver que..."

Em Memorial do Convento, Sebastiana Maria de Jesus é bruxa: ela tinha o dom de enxergar o que ninguém mais podia ver, e por isso foi queimada na fogueira da inquisição. Mas o que Saramago vai agora dizer é tão evidente, que nem é preciso da bruxa para revelar. É que: "...faltando os homens, o mundo para."

Assim como a nora que transporta a água ao andar animal, o mundo gira ao andar dos homens, e tudo perde 0 sentido sem o caminhar. São coisas muito evidentes, assim como é também evidente que a matemática, não sendo dos homens e para os homens, carece de sentido.

Contrariando as evidências, costuma-se dizer que "a matemática é a linguagem que Deus usou para escrever o mundo", uma frase atribuída a Galileu. De fato, a matemática que aprendemos e ensinamos se parece mais com uma linguagem de Deuses do que com algo dos homens e para os homens. "Por vezes é útil pedir à evidência que se justifique", ensinou Benveniste, o linguista ${ }^{3}$, referindo-se à uma outra evidência.

Neste artigo procuramos repensar a matemática a partir das coisas do nosso mundo. Expressões das demandas da vida, a matemática, assim como o discurso, cursa no fluxo dos acontecimentos. Não tem formas exclusivamente objetivas, mas apenas relações que se moldam no contexto, espaço e tempo onde 0 evento se dá. ${ }^{4}$ Como 0 discurso, a matemática é situada.

Sob este ponto de vista, trazemos aqui uma abordagem comprometida com as percepções do dia a dia do brasileiro, tendo como pano de fundo o nosso percurso de país de periferia.

De um lado, o desejo nacional de afirmar-se sobre um padrão ocidental dominante com seus referenciais de sucesso e verdade, que já chegam a nós estabilizados. Como as imposições elitistas das normas do português que falamos, temos as normas da matemática naturalizada, que devemos saber para acompanhar o mundo, mas não devemos questionar e não nos cabe intervir.

De outro lado, o afã por expressão, o drible, a ginga, o batuque, explosões de criatividade, necessidade de produzir o novo para irromper com uma situação de adversidade, de escassez de condições mínimas.

Como percebeu Policarpo Quaresma, o domínio estabelece normas: "o falar e o escrever em geral, sobretudo no campo das letras, se vêem na humilhante contingência de sofrer continuamente censuras ásperas dos proprietários da língua". ${ }^{5} 0$ Major Quaresma solicitou aos senhores congressistas a instituição do Tupi-guarani como língua nacional. Não percebeu o major que ninguém executa "o que não sabe, não pode ou não quer falar". ${ }^{6}$ Decorre daí uma multiplicidade de "falares", linhas de fuga, escapes das normas, que não se fazem reconhecidos nas estruturas dominantes. Seria possível que a inventividade brasileira tão evidente no futebol, na capoeira, na música, dança, literatura não estivesse também presente na matemática, se tudo é parte de um mesmo processo de enfrentamento da realidade?

Buscando perceber estas linhas de fuga da matemática constatamos a necessidade de um esforço desdisciplinar, dessaber as fronteiras. Nem discurso, nem matemática, nem balé, nem samba, nem feijoada, nem xadrez. Mas discurso, matemática, balé, samba, feijoada, xadrez. ${ }^{7}$ 
Sob este ponto de vista, e portanto, pedindo às evidências que se justifiquem, procuramos respostas à pergunta que se segue.

\title{
Porque a matemática precisa ser tão difícil?
}

\author{
Nesta seção apresentamos três referenciais que orientam nossas \\ reflexões sobre a construção do conhecimento, e em particular, sobre a compreensão \\ da matemática como um corpo de saberes emaranhado nas coisas da vida.
}

"O mundo por ser redondo tem por destino embolar", canta Siba Veloso e Fuloresta do Sambå, , o maracatu de baque solto. As manifestações populares chamam atenção por seu aspecto múltiplo, e não pelo que nelas há de plural, empregando aqui estes termos como em Deleuze e Guattari. ${ }^{9} 0$ múltiplo deixa evidente as diferenças que, no coletivo operam juntas, mantendo-se diferentes; o plural resume o coletivo em algo que há de semelhante entre seus indivíduos. 0 maracatu de baque solto é uma multiplicidade de ritmos populares: folia de reis, pastoril, cavalo-marinho, bumba-meu-boi, caboclinho. Combina elemento de festas datadas como o Natal e o Carnaval, com cultos indígenas, louvações à caça e à boa colheita. É também uma tradução das expressões populares no deslocamento do campo para a cidade de Recife - decorrência crise da cultura da cana. A ciranda é dança em roda, com muitas cores e marcada pelo o barulho seco de pés batendo no chão (no cavalo marinho, imitando o som do cavalo). É uma dança contagiante que provoca a adesão das pessoas que estão no entorno. Assim, a roda cresce, e quando já não é mais possível manter-se no espaço, multiplica-se em outra roda interna de modo a estar sempre abrigando. Tem aí muita matemática. No bater dos pés, nos círculos da ciranda, é a matemática daquela gente da zona da mata pernambucana.

Para perceber a matemática da gente, e seu papel no nosso mundo, trabalhamos neste texto sobre três referenciais:

0 primeiro é que o conhecimento, em particular, a matemática, é construído, ou seja, sua compreensão exige abrir mão de um mundo fixado de verdades e aprender a negociar com as múltiplas e heterogêneas concepções de mundo onde se dá esta construção, ou onde ela pretende ter significado.

O segundo é que esta construção é social, ou seja, se estabelece no encontro tensionado entre forças diversas que operam coletivamente. Em outras palavras, a dinâmica das relações constrói os mundos, seus discursos e suas matemáticas.

0 terceiro é que, sendo construída socialmente, é também historicamente comprometida com o coletivo que a enunciou, e portanto, não é difícil para aquele coletivo. A matemática se torna difícil quando ela é imposta como resultado a-histórico, um processo de afirmação de autoridade que atende a uma certa configuração de poder.

Fuloresta canta: "Toda vez que dou um passo o mundo sai do lugar", sabedoria como a de Saramago, que coloca em evidência a pessoa no mundo em que vive e sua ação transformadora. São ideias aqui presentes para nos ajudar na compreensão das matemáticas de cada mundo, em particular, das matemáticas do nosso mundo.

\section{Ideias, linguagem abstrata, coisas do mundo... discursos e matemáticas!}

A partir de Cora Coralina e Paulo Freire vemos a necessidade de manter visíveis as ligações entre um o corpo abstrato de conceitos e as relações com objeto ou situação que the serviu de inspiração. 
Do batuque pernambucano, vamos ver matemática nos sinos de Goiás. Cora Coralina é uma escritora e poetisa brasileira que viveu entre 1889 e 1985. Ela costumava escrever sobre coisas da sua vida, coisas simples do seu dia a dia. A cidade de Goiás, onde cresceu e viveu tem uma forte presença em sua obra. Dona Anica, como era chamada Cora Coralina, ${ }^{10}$ conta:

À cidade de Goiás, embora pequena, não lhe faltam sinos. (...) Cada uma das igrejinhas tem seus sinos em torres separadas com pequenos carrilhões. (...) Os sinos, então, falam, chamam, soluçam, plangem. (...) Muito tempo longe de Goiás, passei a desentender a linguagem dos bronzes e querendo me inteirar das ocorrências badaladas, apelo para a instância superior representada por Júlia, com seus 50 anos de casa velha e sua sabedoria que vai pelo espaço.

-Júlia, é anjinho que estão tocando?

-Não senhora, dona Anica, é pecador.

-Como assim, Júlia?

-O camarim do Senhor dos Passos não toca anjinho, só bate defunto...

-É homem ou mulher, Júlia?

-É homem, dona Anica; a senhora não vê que é só o grossão?

Do percurso da procissão fúnebre aos detalhes do morto, na velha Goiás tudo se compreende pelas badaladas. É uma congruência de pensamentos que não requer explicações para quem, como Julia, faz parte daquele coletivo. Mas, observou Dona Anica, para aqueles que vêm de fora, o que é "evidente" demanda explicações. É então necessário refazer os laços entre a linguagem dos sinos e as coisas da vida. É precisamente aí que reside a sabedoria de Julia: ela é capaz de situar a linguagem abstrata, refazendo as ligações entre os sons dos sinos e a vida de Dona Anica. A linguagem dos sinos é uma construção abstrata, como matemática, e também como a matemática, torna-se difícil quando desconectada das coisas da vida.

Um outro brasileiro que também levou em conta essas ligações entre a linguagem abstrata e as coisas da vida foi Paulo Freire, educador que viveu entre 1921 e 1997. No início dos anos sessenta, ele alterou práticas e concepções da educação de adultos no Brasil. 0 país vivia um momento de questionamento com relação à educação. A elite intelectual prestava uma especial atenção às taxas de analfabetismo, e os movimentos de cultura popular disseminados pelo país voltavam os olhos às causas sociais. Em Pernambuco, em 1960, durante a gestão de Miguel Arraes, surgiu o MCP - Movimento de Cultura Popular que, inspirado em modelo francês, abordava a educação de base, 0 analfabetismo de adultos e a conscientização popular. Em reuniões com grupos populares se discutiam temas diversos que eram sugeridos pelo grupo e pelos educadores. A riqueza das discussões em grupos inspirou Freire a dar um passo em direção ao abstrato, à construção de seu sistema de sinais, sua matemática'11.

Se é possível fazer isso, alcançar esse nível de discussão com grupos populares, independentemente de eles serem ou não alfabetizados, por que não fazer o mesmo numa experiência de alfabetização? Por que não engajar criticamente os alfabetizandos na montagem de seu sistema de sinais gráficos enquanto sujeitos dessa montagem e não enquanto objetos dela?

Naquele tempo utilizavam-se cartilhas, com combinações de letras e frases montadas pela repetição de sons. Por exemplo, "vovó viu a uva". Todo o método de alfabetização prosseguia daí a partir de repetição e reprodução de frases descontextualizadas, um sistema de sinais (uma matemática) desconectada da vida.

As cartilhas marcaram época. Hoje, pode-se encontrar facilmente pela Internet depoimentos emocionados sobre o método, nos permitindo ver que ainda ecoa nas cabeças o som das vozes das crianças em 
processo de domesticação' ${ }^{12:}$ "Os que foram alfabetizados com a Sodré devem-se lembrar de 'A pata nada'. Os comportados alunos repetiam em voz alta, como num coral, as frases da lição, comandados pela professora. Era a associação do som com as letras. E funcionava!". Os relatos saudosos não deixam ver o contingente de adultos analfabetos que não conseguiram acompanhar o método de adestramento:

A menina Maria Roza, na pequena escola de Tambaú, João Pessoa, Paraíba, em 1945, foi convidada pela professora para fazer uma leitura em voz alta. Pegou seu livro e foi para frente da sala para ler ao lado da professora. "Não precisa trazer o livro. Eu vou lhe dar o texto". Maria Roza recebeu o texto das mãos da professora, mas não leu: "Eu só sei ler no meu livro...". Gargalhada geral, e Maria Roza não quis mais voltar mais à escola... mais uma menina paraibana analfabeta. ${ }^{13}$

Recusando a domesticação, Paulo Freire propôs a substituição das cartilhas por um método diferente que tinha como ponto de partida a reflexão do indivíduo com relação à sua própria condição social. Com isso, envolvia a pessoa na construção de seu processo de aprendizagem. Da fala de cada um sobre sua própria vida, Paulo Freire retirava as palavras e frases para serem usadas na expressão escrita, o que ele chamou de "levantamento do universo vocabular". ${ }^{14}$ Assim, sua proposta para a alfabetização de adultos considerava palavras e temas de vida e frases contextualizadas em reflexões críticas sobre a condição social. Ou seja, mantendo aparente o processo de construção da escrita, procurava deixar evidentes os vínculos da linguagem abstrata com as coisas da vida, tal como fez Júlia com a linguagem dos sinos.

0 sucesso do método de Paulo Freire foi reconhecido e acolhido pelo governo brasileiro, que então, sob a presidência de João Goulart, deu início ao Programa Nacional de Alfabetização. Mas, em seguida, ocorreu o golpe militar de 1964. Sob os olhos do governo repressivo, a abordagem de Freire foi considerada subversiva e por isso foi interrompida. Conta Moacir Gadotti15:

As primeiras experiências do método começaram na cidade de Angicos (RN), em 1963, onde 300 trabalhadores rurais foram alfabetizados em 45 dias. No ano seguinte, Paulo Freire foi convidado pelo presidente João Goulart e pelo Ministro da Educação Paulo de Tarso C. Santos, para repensar a alfabetização de adultos em âmbito nacional. O golpe militar, no entanto, interrompeu os trabalhos bem no início e reprimiu toda a mobilização já conquistada. (...) Paulo Freire foi exilado pelo golpe militar de 64, porque a Campanha Nacional de Alfabetização no Governo João Goulart estava conscientizando imensas massas populares que incomodavam as elites conservadoras brasileiras. Passou 75 dias na prisão acusado de "subversivo e ignorante".

Freire continuou seu trabalho em educação no exílio, sob os mesmos princípios: reflexões críticas, diálogo e participação.

Tempos mais tarde, já como Secretário de Educação do Estado de São Paulo na passagem dos anos 80 para os 90, insistindo na possibilidade de uma educação matemática dialógica, Paulo Freire viria a dizer: "No momento em que ele (o aluno) aprende a rigorosidade que a matemática sugere ele deve estar aberto a uma relação ou uma compreensão do social ligado a matemática". ${ }^{16}$

Os sons dos sinos de Goiás nos mostram que, para comunicar, a linguagem exige uma conexão com as coisas do mundo da vida. Da mesma forma, Freire argumentou que a alfabetização muito tem a ver com a compreensão do homem em seu lugar de vida, suas conquistas e sua relação com o mundo. Nos dois casos vemos sistemas de signos, linguagens abstratas, matemáticas, e percebemos que 0 afastamento entre o corpo abstrato e seu objeto dificulta a compreensão. Se assim falam os sinos, se assim se aprende a escrita ... 


\title{
... haveria de ser diferente com a expressão matemática?
}

\author{
Nesta seção elaboramos, através das falas de Einstein, Asimov e James, o processo pelo qual \\ a matemática se configura como um saber autoritário, difícil e elitizado.
}

Em 27 de janeiro de 1921 o físico Albert Einstein proferiu a palestra "Geometria e Experiência" na Academia Prussiana de Ciências em Berlim. Segundo uma versão expandida traduzida para a língua inglesa ${ }^{17}$, e que aqui traduzimos para o português, Einstein teria iniciado seu discurso falando sobre a matemática: "A razão pela qual a matemática goza de especial estima, acima de todas as outras ciências, é que suas leis são absolutamente certas e incontestáveis, enquanto que todas as outras ciências são, até certo ponto discutíveis e em constante perigo de serem derrubadas por fatos recém-descobertos."

Ele situa a matemática como uma ciência acima de todas as outras, absolutamente certa e incontestável. Por um lado, ele entende a matemática como construção da mente humana. Por outro lado, ele afirma que essa construção é independente da experiência. Assim, Einstein separa o homem (a mente) do seu mundo (a experiência), e questiona indignado: "Como pode ser que a matemática, sendo, afinal, um produto do pensamento humano que é independente da experiência, seja tão admiravelmente adequada aos objetos da realidade?" Desta indignação, Einstein antecipa questões matemáticas que só teriam um entendimento mais amplo dez anos depois, década de 1930, a partir do trabalho de Kurt Gödel nos Teoremas da Incompletude. No mesmo discurso de 1921, ele conclui: "Na medida em que as leis da matemática se referem à realidade, elas não estão certas; e, à medida em que estão certas, eles não se referem à realidade".

Em 1988, quase sete décadas após o discurso de Einstein vemos ainda a louvação da matemática por seu rigor, exatidão e certeza. 0 escritor Isaac Asimov, um divulgador da ciência, escreveu o prefácio da segunda edição do livro de História da Matemática18: "Nada que se refere à humanidade nos aparece tão bem como a matemática. Aí, e só aí tocamos a mente humana em seu ápice". Nestes termos, a matemática parece mesmo a linguagem de deuses que Galileu teria mencionado, ou de gênios, na percepção do menino nordestino, cujo talento matemático escapou à matemática escolar ${ }^{19}$ :

Lamentavelmente, o que a gente vem fazendo, e eu sou um brasileiro que paga, paga caro... Eu não tenho dúvida nenhuma que dentro de mim há escondido um matemático que não teve chance de acordar, e eu vou morrer sem ter despertado esse matemático, que talvez pudesse ter sido bom. Bem, uma coisa eu acho, que se esse matemático que existe dormindo em mim tivesse despertado, de uma coisa eu estou certo, ele seria um bom professor de matemática. Mas não houve isso, não ocorreu, e eu pago hoje muito caro, porque na minha geração de brasileiras e brasileiros lá no Nordeste, quando a gente falava em matemática, era um negócio para deuses ou gênios. Se fazia uma concessão para o sujeito genial que podia fazer matemática sem ser deus. E com isso, quantas inteligências críticas, quantas curiosidades, quantos indagadores, quanta capacidade abstrativa para poder ser concreta, perdemos.

Tendo em mente os muitos meninos e meninas matemático(a)s que estão por despertar, verificamos que é sob o amparo de uma ciência recortada em disciplinas que a matemática é tomada como "de especial estima, acima de todas as outras ciências", pois torna-se possível sobrepor em importância um recorte a outro. Tendo sido proferidas por Einstein, as palavras sobre a matemática ganham uma força especial, empurrando para frente certas convicções a respeito da ciência cujo processo de construção se firmou durante a era moderna. Uma destas convicções transparece no trecho "...constante perigo de serem derrubadas por fatos recém-descobertos": a pressuposição de que os fatos estão postos no mundo, e o papel do cientista é descobri-los. A matemática, estaria ali para estabelecer a ponte entre a fala do cientista descobridor e o mundo já pronto. Esta ponte é, porém, efêmera, pois uma vez legitimada, ou seja, havendo acordo na comunidade científica com relação à sua adequação, a ponte se desfaz, e fica a teoria, matemática 
enunciada sem as particularidades que Ihe serviram de inspiração. Assim, adquire uma aparência neutra (limpa) e universal. Este processo, que ressoa como os sinos de Goiás aos ouvidos de D. Anica, já havia sido compreendido por William James, na virada do século XIX para XX. Ele chamou de "salto mortal" a uma separação entre coisas e ideias que termina por causar um salto em direção ao simbólico. É mortal porque, ao esconder a cadeia de vínculos entre uma ideia (forma) e o mundo-da-vida (matéria, coisa, objeto), dificulta, ou torna inalcançável a compreensão. D. Anica não compreende os sinos, necessita de Júlia para reestabelecer os vínculos entre a linguagem abstrata e o mundo da vida. A explicação de Julia desfaz o salto mortal, como sugeriu William James²0:

Tudo o que precisamos é restaurar alguma parte, não importa o quão pequena, do que havíamos jogado fora. No caso do abismo epistemológico o primeiro passo razoável é lembrar que o abismo foi preenchido por ALGUM material empírico, seja ideacional ou sensacional, que performou ALGUMA função ligadora e nos salvou do salto mortal.

Ao omitirem-se os vínculos entre ideias e mundo, as entidades às quais estas ideias se referem perdem a sua história de construção, assumindo, portanto, uma existência autônoma, independente das coisas da vida e dos homens. Os matemáticos se veem no papel de descobrir as entidades matemáticas, e não de construí-las. Então a história da matemática passa a ser o relato das descobertas ao longo do tempo (uma linha do tempo recheada de resultados), sendo que cada resultado em particular é destituído da sua história (de seu processo de construção). Como se vê no prefácio de Asimov, a perfeição da matemática resulta de uma abordagem linear e purificada em que não se deixa aparente o seu interagir com o mundo:

A matemática é um aspecto único do pensamento humano e sua história difere na essência de todas as outras histórias. Com o passar do tempo, quase todo campo de esforço humano é marcado por mudanças que podem ser consideradas como correção e/ou extensão. (...) Agora vemos o que torna a matemática única. Só na matemática não há correção significativa, só extensão. Uma vez que os gregos desenvolveram o método dedutivo, o que fizeram estava correto, correto para todo o sempre. Euclides foi incompleto e sua obra foi enormemente estendida, mas não teve que ser corrigida. Seus teoremas, todos eles, são válidos até hoje. Ptolomeu pode ter desenvolvido uma representação errônea do sistema planetário, mas o sistema de trigonometria que ele criou para ajudá-lo em seus cálculos permanece correto para sempre. (...) Cada grande matemático acrescenta algo ao que veio antes.

A abordagem linear, supostamente neutra e universal, ampara uma matemática hermética, uma linguagem compreendida somente no âmbito de uma comunidade de matemáticos, autoritária, difícil e elitizada. É autoritária, porque é imposta aos que não fazem parte daquele coletivo de matemáticos, e por isso, não conseguem acompanhar seu percurso de construção. Sendo autoritária, torna-se também difícil, uma vez que só admite questionamentos em seus próprios termos (através de suas próprias justificativas racionais), e portanto restringe o espaço de argumentações àqueles que têm pleno domínio. E daí, é também elitizada, porque dá a entender que é feita somente para aqueles que supostamente teriam uma habilidade especial.

Voltamos a Pernambuco através do estudo de Carrahier, Carrahier, e Schliemann ${ }^{21}$. Eles procuraram observar a matemática da vida e a matemática escolar trazendo para sua pesquisa a menina que vendia coco na barraca em Pernambuco. Ela não era capaz de acompanhar a matemática da escola. Conhecia os algoritmos para fazer as contas, mas não sabia aplicar porque não entendia como aquilo podia dar o resultado certo. Para ela, a "conta armada" era difícil, não era como fazer o troco para os cocos. Segundo os critérios escolares, ela era decididamente um fracasso na matemática. Observando o conhecimento matemático dominado pela menina, o artigo Na vida dez, na escola zero conclui que o fracasso escolar é o fracasso da escola (e não do aluno) e localiza-se, dentre outros motivos indicados, "na incapacidade de estabelecer uma ponte entre o conhecimento formal que deseja transmitir e o conhecimento prático do qual a criança, pelo menos em parte, já dispõe", ou seja, falta colocar em evidência os vínculos das ideias com as coisas do mundo. 


\title{
Saber legitimado, autoridade do que não se pode questionar
}

\author{
Consideramos o processo de legitimação do conhecimento e maneiras \\ como o conhecimento dito científico, passa a ser imposto. A partir daí, analisamos \\ uma rede de poder sobre a qual se sustenta a matemática institucionalizada.
}

Convencido de que o conhecimento científico é uma construção social, Ludwick Fleck, na década de 30, buscou compreender os processos de legitimação da ciência. Ele disse22: “[u]ma legitimação, portanto, somente é possível onde, no fundo, já não é mais necessária, a saber, entre pessoas da mesma constituição mental, que pertencem ao mesmo estilo de pensamento e com uma formação específica semelhante".

De 1964 a 1969, exilado no Chile, Paulo Freire trabalhou no Instituto de Capacitação e Investigação em Reforma Agrária (ICIRA), colaborando na concepção da implantação de reformas de base. 0 Chile passava por um momento de importantes mudanças sociais, sob o governo de Eduardo Frei, eleito com o apoio da Frente de Ação Popular de Esquerda. Paulo Freire refletiu sobre o trabalho do agrônomo extensionista encarregado de substituir os procedimentos empíricos dos camponeses por "técnicas apropriadas", ou seja, técnicas legitimadas pela academia. Estes agrônomos enfrentavam, porém, a resistência dos camponeses, que praticavam o cultivo empregando o saber construído através das gerações. Configurou-se o seguinte:

Para o agrônomo extensionista, o camponês empregava procedimentos baseados em crença, uma espécie de mágica. 0 ponto de vista do agrônomo extensionista se justifica, pois ele não havia acompanhado o processo de construção de um saber constituído ali, e transmitido através das gerações. Para ele o saber do camponês, a crença, era um saber a-histórico, autônomo, que se justifica em si próprio, como uma mágica.

Para o camponês, o agrônomo extensionista impunha procedimentos baseados em ciência, também uma espécie de mágica. 0 camponês não havia acompanhado o processo de construção daquele saber produzido fora dali, nas academias. Para ele o saber dos técnicos, a ciência, era um saber a-histórico, autônomo, justificado em si próprio, como uma mágica.

Assim, a ciência era para o camponês um saber autoritário tanto quanto as técnicas camponesas o eram para 0 agrônomo extensionista. Entretanto, aos olhos da política agrária do Chile na época, a legitimação da academia soava mais forte do que a legitimação da tradição familiar.

Paulo Freire propôs substituir (termo e práticas) "agrônomo-extensionista" por "agrônomo-educador", sugerindo que no lugar de adestrar o camponês no uso das técnicas pudesse elaborar em diálogo com ele os procedimentos a adotar, e argumentou: “0 autoritarismo não está necessariamente associado a repressões físicas. Dá-se também nas ações que se fundamentam no 'argumento da autoridade': 'isto é assim porque é. A técnica já o disse. Não há que discordar, mas sim que aplicar'..". 23

É uma cena não muito distante da tradição escolar da matemática onde a autoridade de um conhecimento dito exato e objetivo se sobrepõe a qualquer possibilidade de construção alternativa. A prova formal de um enunciado é o ponto final de qualquer controvérsia a respeito do enunciado: - Se está provado é porque é verdade, costuma-se dizer, indicando que a discussão é desnecessária. - Se não entendeu, leia a prova, costuma-se dizer, mesmo quando se sabe que quem não entendeu o enunciado, provavelmente não entenderá também a prova: encadeamento formal de símbolos, aplicações de regras e justificativas matemáticas que nem sempre permitem perceber a intuição que há por trás.

Sobre essas reflexões a respeito de legitimação e autoridade do conhecimento, podemos perceber que a matemática se estabelece sobre uma rede de poder que privilegia: os sujeitos matemáticos, as entidades matemáticas e os objetos que aderem à matemática.

Os sujeitos matemáticos são considerados são inteligentes, deuses ou gênios. Eles dominam a linguagem abstrata e sabem lidar com a "verdade" através das provas. 
As entidades matemáticas são consideradas "inquestionavelmente verdadeiras". Isto deixa de fora indagações a respeito de sua constituição. Assim, por exemplo, as leis da aritmética, os números, ou ainda, as unidades de medida são tomados como se sua existência independesse das coisas humanas. Ainda mais, o fato de que estas construções vêm operando satisfatoriamente (por exemplo, nos artefatos tecnológicos) parece indicar a impossibilidade de outras construções matemáticas também satisfatórias.

Os objetos que aderem à matemática são não somente os que têm o seu sucesso atestado pelas provas formais como programas com certificado de correção ou teoremas matemáticos, mas também todos aqueles objetos do dia a dia que se apoiam em índices, taxas, estatísticas, quantificadores. Estes tomam partido daquilo que os números inspiram de certeza, verdade, objetividade, exatidão. É a tecnologia da confiança, nos termos de Porter. ${ }^{24}$

\title{
Modos de pensamentos que transpassam disciplinas
}

\author{
Nesta seção argumentamos que expressão linguística dos conceitos acompanha a necessidade de \\ fazê-los operar para transformar o mundo em que vivemos. Os conceitos são expressos na lin- \\ guagem que é confortável a quem quer falar. Os matemáticos se expressam na linguagem formal, \\ matemática, e isto faz parecer que dizem coisas exclusivamente matemáticas. O jargão disciplinar \\ não deixa transparecer o caráter situado e desdisciplinar do pensamento.
}

Foucault abordou o processo através do qual a loucura se constituiu como objeto de saber para a medicina conformando-se em dois polos: o polo dito subjetivo da experiência da loucura e o polo dito objetivo da doença mental. Em entrevista à André Berten, ${ }^{25}$ Foucault apontou como fio condutor de sua filosofia questões que se passam ao redor de nós: quem nós somos, o que se passa hoje. É uma preocupação na compreensão do espaço e tempo, que hoje nos ampara nas propostas de abordagens situadas, ou seja, comprometidas com as questões do local e do momento de onde são enunciadas.

Sob uma perspectiva situada, a experiência matemática não se faz aparente necessariamente na matemática institucionalizada, legitimada pela academia. Ela está presente enquanto música, enquanto futebol, enquanto literatura, ou seja, como expressão de questões coletivas e sociais, diferentes maneiras de manifestação de saber, e pode ser decifrada desde que haja uma certa disposição de acolhimento àquilo que escapa aos padrões legitimados.

Reconhecer a experiência matemática nesses espaços de expressão criativa parece um contra-senso. É uma recusa a aceitar a verdade matemática através de suas próprias justificativas racionais para percebê-la no dispositivo ${ }^{26}$ da matemática, espaços de intolerância dos matemáticos. Mas é precisamente nestas intolerâncias (subjetividades, informalidades, expressão e criação) que se encontram as possibilidades de produção daqueles que se situam fora dos centros hegemônicos.

Foucault explicou a André Berten na entrevista de 1981: "ao invés de interrogar a lei ou em que se funda a lei, pegar o crime como ponto de ruptura em relação ao sistema. Tomar a prisão como aquilo que vai esclarecer o que é 0 sistema penal". ${ }^{27}$ Da mesma forma, explicou Foucault, fazer a história da loucura para interrogar nosso sistema de razão. 0 pensamento assume o contra-sentido: uma volta sobre si próprio (recorrência, reflexão, auto-referência) a partir de um espaço de negação (ilegalidade, insanidade). É uma estratégia que se tem mostrado produtiva não somente porque o olhar que parte dos espaços ilegítimos permite melhor compreender a legitimidade, mas também porque dá visibilidade ao inesperado, isto é, ao que está fora do enquadramento das abordagens legitimadas. Este modo de pensamento pode ser percebido em campos considerados não-exatos, como fez Foucault ao abordar a loucura, mas, da mesma forma, pode também ser percebido em domínios considerados exatos, como vemos a seguir. 
Para compreender propriedades de enumeração no conjunto dos números reais, George Cantor, em fins do século XIX, apresentou um número real cujo próprio mecanismo de construção como número real o colocava fora da enumeração: um elemento produzido no âmbito do domínio, mas que escapou à legalidade deste domínio. Esta técnica denominada diagonalização, ${ }^{28}$ é a expressão matemática de um modo de pensar muito próximo ao que Foucault chamou de heterotopologia: 0 estudo do lugar de fora, dos que têm o comportamento desviante com relação à maioria ou à norma vigente:

(...) o que me interessa são, entre todos esses posicionamentos, alguns dentre eles que têm a curiosa propriedade de estar em relação com todos os outros posicionamentos, mas de um tal modo que eles suspendem; neutralizam ou invertem o conjunto de relações que se encontram por eles designadas, refletidas ou pensadas. Esses espaços, que por assim dizer estão ligados a todos os outros; contradizendo, no entanto, todos os outros posicionamentos $(\ldots)^{29}$

A diagonalização matemática serviu de amparo formal para inesperados resultados matemáticos do início do século XX que, numa leitura atual, contribuíram para evidenciar a impossibilidade de se recusar as matemáticas dos mundos. Vejamos:

Os muitos avanços expressos na matemática no século XIX, envolveram os matemáticos do eixo Europa-Estados Unidos em uma série de questionamentos com relação às questões fundamentais da matemática, desencadeando os chamados movimentos de fundamentação da matemática do início do século XX. As discussões se amparavam em concepções como: realidade fixada, verdade única e pronta, abordagem reducionista e contínua, pressuposto de que 0 todo não é mais do que a junção das partes e meta de abraçar a totalidade. Estas ideias vinham se consolidando a partir do século XVII, tendo, na concepção cartesiana da ciência expressa no Discurso sobre o Método para bem conduzir a razão e buscar a verdade nas Ciências, de 1634, uma forte referência.

Na década de 1930, em meio ao sentimento totalizante de que a matemática (um sistema formal) seria capaz de provar qualquer enunciado (expresso no próprio sistema), o matemático Kurt Gödel surpreendeu-se, e surpreendeu a comunidade matemática do eixo Europa-Estados Unidos. Ele mostrou a existência de enunciados que, embora expressos matematicamente (em um sistema formal capaz de abraçar a aritmética), não poderiam ser provados no próprio sistema: a incompletude da matemática. ${ }^{30}$

Para provar a incompletude, Gödel inspirou-se no trabalho de Jules Richard que confrontou a expressão em língua natural de propriedades de números com números definidos por expressão em língua natural: "Então: Todos os números que podemos definir através de um número finito de palavras formam um conjunto enumerável. Aqui está agora a contradição: podemos formar um número que não pertence a esta enumeração". ${ }^{31}$ Referindo-se a Richard, Gödel traduziu para a linguagem matemática uma sentença que afirma algo sobre ela própria: "esta sentença não tem prova" e construiu a prova matemática de que nem a veracidade nem a falsidade desta sentença poderiam ser provadas em um sistema formal suficientemente expressivo para abraçar a aritmética. Ambientada no raciocínio diagonal, que teve, a partir de Cantor, a sua expressão no âmbito da matemática, a incompletude também se desenrolou em uma reflexão (auto-referência) e uma negativa: compreender os sistemas formais abordando o que não pode ser formalizado, o mesmo modo de pensamento que mais tarde, já comentamos, também se fez presente no argumento de Foucault. Vemos, a seguir, outras manifestações na matemática deste modo de pensamento:

Antes de Gödel, em 1902, também empregando o raciocínio auto-referente e uma negação, o matemático Bertrand Russell já havia percebido e procurou explicações para um paradoxo na teoria dos conjuntos. Ele expressou seu espanto em uma carta a Gottlob Frege 32: "Seja w o predicado: ser um predicado que não pode ser predicado de si mesmo. W pode ser predicado de si mesmo? A partir de cada resposta seu oposto segue." Está clara aqui a auto-referência: ser predicado de si mesmo, e a negação: não pode ser predicado de si mesmo. 0 paradoxo surge quando o predicado é aplicado a alguma expressão de si mesmo: "Pode w ser predicado de si mesmo? A cada resposta segue-se o seu oposto".

Na época, a expectativa de totalização e segurança depositada na matemática fez despertar especial atenção à inconsistência (no caso do paradoxo de Russell), e à incompletude (no caso do Teorema de Gödel), um certo tom pessimista que, mais tarde, em 1936, se tornaria ainda mais alarmante com a enunciação, por Alan Turing da não- 
-computabilidade: números impossíveis de serem calculados por qualquer processo mecânico ${ }^{33}$. Não despertou muita atenção naquele momento o fato de que Russell, Gödel e Turing foram também capazes de observar o aspecto produtivo que estes espaços de negação trazem consigo, justamente aquilo que faz emergir o inesperado, o que não se consegue perceber pelo olhar racional dos espaços legitimados, como disse Foucault a respeito da loucura ${ }^{34}$ :

(...), a loucura fascina porque é um saber. (...) Este saber, tão inacessível e temível, o Louco o detém em sua parvoíce inocente. Enquanto o homem racional e sábio só percebe desse saber algumas figuras fragmentárias - e por isso mesmo mais inquietantes -, o Louco o carrega inteiro em uma esfera intacta: essa bola de cristal, que para todos está vazia, a seus olhos está cheia de um saber invisível.

Russell percebeu que o mecanismo expresso em termos de predicados podia ser expresso em termos de conjuntos ${ }^{35}$ : $\{X \mid X \notin X\}, 0$ conjunto formado por todos os conjuntos que não pertencem a si próprios. Também nessa forma levaria ao paradoxo: pertenceria este conjunto a si próprio? A cada reposta segue-se o seu oposto. No entanto, o processo de experimentação em $\{X \mid X \notin X\}$ desdobra-se infinitamente: tomando-se, por exemplo o conjunto $\left\{{ }^{*}\right\}$, podemos verificar se ele pertence a si mesmo. Vemos que isto não ocorre, pois se $\left\{{ }^{*}\right\}$ pertencesse a si próprio, deixaria de ser ele mesmo e passando a ser $\left\{{ }^{*},\left\{{ }^{*}\right\}\right.$. Mas nesse caso, o conjunto em questão seria $\left\{{ }^{*},\left\{{ }^{*}\right\}\right\}$ e passaríamos a verificar se este pertence a si mesmo. Isso geraria $\left\{{ }^{*},\left\{{ }^{*}\right\},\left\{{ }^{*},\left\{{ }^{*}\right\}\right\}\right.$, e assim indefinidamente. É um processo que, ao escapar da contradição, se desdobra em uma construção infinita.

Buscando livrar a Teoria dos Conjuntos do paradoxo, Russell concebeu sua Doutrina de Tipos ${ }^{36}$ separando entidades matemáticas em uma hierarquia de tipos, onde cada tipo seria uma construção sobre 0 anterior. Evitava 0 paradoxo sintaticamente, pela imposição de que a operação de pertinência só se aplicasse entre um tipo e outro imediatamente posterior, impossibilitando a construção reflexiva $X \notin X$. Ele define: "Podemos observar que $x \in x$ só pode ter significado quando $x$ é de um tipo de ordem infinita, já que em $x \in u$, u precisa sempre ser de um tipo maior de um do que $x$; mas a classe de todas as classes é, é claro, de um tipo de ordem infinita."

Como já foi argumentado por Foucault, abordar os espaços ilegítimos nos permite melhor compreender a legitimidade, ou, no caso da matemática, abordar os espaços de incompletude nos permite melhor compreender a completude. No caso da matemática da década de 1930, disse matemático inglês Alan Turing ${ }^{37}$ que Gödel, ao apontar a existência de uma sentença incapaz de ser abraçada pelos sistemas formais, havia também percebido um certo processo de completação em sistemas formais: “0 bem conhecido teorema de Gödel mostra que todo o sistema de lógica é, em certo sentido, incompleto, mas, ao mesmo tempo, indica meios pelos quais a partir de um sistema lógico $L$ um sistema mais completo L' pode ser obtido". Desenvolvendo esta ideia, Turing propôs a incorporação passo a passo em um sistema incompleto de um enunciado que o fazia incompleto gerando, a cada passo, um novo sistema formal: "A partir de um sistema $L$ de lógica, outro mais completo $L$ ' pode ser obtido. Repetindo-se o processo alcançamos a sequência $L, L 1=L^{\prime}$, $\mathrm{L}_{2}=\mathrm{L}_{1}{ }^{\prime}, \mathrm{L} 3=\mathrm{L} 2^{\prime}, \ldots$ de lógicas, cada uma mais completa do que a precedente". Ele observou que, em decorrência do Teorema de Gödel, este processo nunca atinge a completude. É uma busca infinita pela completude sem, no entanto, jamais alcançá-la. Ainda assim, é uma busca produtiva pois, como ele diz, cada lógica é mais completa que a precedente.

Turing, assim como Gödel e Russell, atentam a um mecanismo que parece correr no sentido inverso da totalização tão perseguida na época (década de 1930). É um moto-contínuo que faz a matemática estar sempre a se renovar, como um mecanismo humano da vida.

Paulo Freire ${ }^{38}$ disse, ao abordar a prática educativa, é um "permanente movimento de procura, de busca". Estava se referindo a um mecanismo que chamou de inconclusão:

(...) a prática educativa se funda não apenas na inconclusão ontológica do ser humano, mas na consciência da inconclusão. É em cima desses dois pés, de um lado a minha inconclusão, do outro a minha consciência da inconclusão, é aí que se funda a educação. (...) Você imagine que incongruência seria que ser inconclusos como somos e conscientes da inconclusão, não nos lançássemos num permanente movi- 
mento de procura, de busca. O ser que não procura é aquele que sendo inconcluso não se sabe inconcluso. Exemplo: a jaboticabeira que eu tenho no quintal da casa é inconclusa também, porque o fenômeno da inconclusão é um fenômeno vital, não é exclusivo do ser humano. Mas o nível de inconclusão da jaboticabeira não tem nada a ver com meu nível de inconclusão. Ela é inconclusa, como é inconcluso meu pastor alemão no quintal, mas eles não se sabem inconclusos. No caso da gente, a gente assumiu a inconclusão e ao assumir a inconclusão, a gente é levada à busca.

Percebemos aqui uma grande afinidade entre a argumentação de Paulo Freire e a argumentação dos matemáticos do início do século XX. Já dissemos que o Paradoxo de Russell, bem como a prova do Teorema de Gödel, empregam uma senteça auto-referente na negativa: um predicado não aplicável a si mesmo, uma sentença que afirma a sua própria indemonstrabilidade. 0 argumento de Freire é sobre a consciência da própria inconclusão. Ele se desdobra através de uma propriedade negada (ser não-conclusivo) e uma reflexão (consciência de ser não-conclusivo). A partir desta combinação de elementos, Freire aponta o que seria uma incongruência: ser inconclusivo, e consciente da própria inconclusão, e não ser imerso em um movimento permanente de busca. A percepção da inconclusão resulta em movimento de busca, da mesma maneira como a percepção de incompletude resulta a busca pela completude.

Identificamos um modo de pensar que se apresentou de diversas maneiras ao longo do século XX. Exibiu uma dimensão produtiva, através de um loop infinito (no caso do pensamento matemático), ou de uma busca constante (nas palavras de Paulo Freire), ou ainda como uma possibilidade de fazer emergir o que está fora do enquadramento (na abordagem foucaultiana). 0 mesmo modo de pensar também mostrou uma dimensão improdutiva, no sentido em que não atendia às expectativas de cada época: o paradoxo e a incompletude, no contexto da busca pela matemática consistente e completa e a impossibilidade de operar somente nas próprias justificativas racionais no contexto mais geral das ciências ditas não exatas.

\title{
Os mundos reivindicam suas próprias matemáticas
}

Fechamos este texto concluindo que a invenção dos conceitos resulta da reflexão sobre as exigências da vida. A dinâmica das relações constrói os mundos, seus discursos e suas matemáticas.

No Rio de Janeiro da década de 30 a boemia carioca brincava com tipos na voz de Noel Rosa. ${ }^{39}$ Ficava ali evidente uma compreensão geral a respeito do mecanismo de classificação, o conceito de tipos expresso de um jeito que em nada se parece com o que se considera matemática:

\author{
Tipo 0 (Noel Rosa) \\ Você é um tipo que não tem tipo \\ Com todo tipo você se parece \\ E sendo um tipo que assimila tanto tipo \\ Passou a ser um tipo que ninguém esquece \\ 0 tipo zero não tem tipo \\ Quando você penetra no salão \\ E se mistura com a multidão \\ Você se torna um tipo destacado \\ Desconfiado todo mundo fica \\ Que o seu tipo não se classifica \\ E você passa a ser um tipo desclassificado \\ Eu até hoje nunca vi nenhum \\ Tipo vulgar, tão fora do comum
}


Que fosse um tipo tão observado

Você ficou agora convencido

Que o seu tipo já está batido

Mas o seu tipo é o tipo do tipo esgotado.

No mesmo período, início do século XX, Europa e Estados Unidos, lugares de produção científica legitimada, debatiam conceitos que dariam fundamento à matemática como ciências exatas. Como já foi dito aqui, Russell elaborava a sua "Doutrina dos Tipos" para expulsar da matemática um tipo que não tem tipo, os paradoxos. Qualquer sistema se trivializa na presença dos paradoxos: sendo um tipo que assimila tanto tipo, tudo dele se deriva, e portanto, nada mais se distingue. Desconfiado todo mundo fica que o seu tipo não se classifica, passa a ser um tipo desclassificado: deve ficar do lado de fora de qualquer teoria que se preste para matemática. Parece ser um tipo que ninguém esquece: presente nas discussões filosóficas desde os gregos antigos (Eubilides de Mileto, século IV a.C.) é um tipo vulgar, tão fora do comum, e paradoxalmente, um tipo tão observado. Porém, como já foi dito aqui, disciplinando a relação de pertinência, Russell impediu a expressão do paradoxo na teoria de conjuntos. Tornou-se, o paradoxo, um tipo do tipo esgotado?

Afastando os tipos da questão dos paradoxos, em outros tempos as linguagens computacionais apresentaram outras justificativas para a adoção de uma matemática tipada. A separação em tipos dos valores a serem computacionalmente representados permitiria uma melhor escolha dos recursos computacionais para implementá-los, bem como para implementar suas operações características. Assim, surge FORTRAN, ${ }^{40}$ em 1957, suportando tipos inteiros e reais (fixed point e float point), e a possibilidade de agrupar esses tipos em matrizes de um a três índices. A partir da década de 1970 os tipos foram pouco a pouco se tornando um conceito central nas linguagens de programação, não mais pela necessidade de uso eficiente dos recursos computacionais (que já não eram tão caros), mas como mecanismo facilitador de representação das abstrações matemáticas. As linguagens passaram a contar com unidades de programação que permitiam ao programador definir, de maneira mais próxima do que se pretendia representar, um conjunto de valores e um conjunto de operações para manipular estes valores. Daí, evoluiu-se para os conceitos de classes e objetos, hoje muito empregados nas linguagens contemporâneas. ${ }^{41}$ Além do uso na programação, os tipos também aparecem de forma muito marcante na descrição das linguagens de programação (gramática formal), onde cada componente linguístico pertence a uma categoria bem delimitada (um tipo).

Na matemática escolar, no Brasil, os tipos não se fizeram evidentes na Teoria dos Conjuntos. Em meados da década de 1950 professores de matemática no Brasil vinham questionando o fracasso do ensino da matemática. ${ }^{42}$ Educadores brasileiros, motivados pelas propostas de mudanças que vinham ocorrendo a nível mundial, aproveitaram a ocasião para promover uma série de debates para repensar o ensino da matemática e democratizar o conhecimento matemático. Embora as queixas fossem no sentido de reivindicar uma maior contextualização do ensino na realidade brasileira e menor "decoreba", o movimento assumiu os rumos internacionais em que a abstração, rigidez e formalização vinham se destacando. Assim, os currículos brasileiros adotaram a Matemática Moderna, uma abordagem fortemente centrada nas ideias do grupo francês Bourbaki, em que as estruturas (algébricas: grupo, anel, corpo, etc, de ordem: reticulados e topológicas: espaços métricos e topológicos) tinham um papel dominante, e com elas, a abstração e a dedução formal. Defendia Bourbaki: "Desde os gregos, quem diz matemática diz demonstração". ${ }^{43}$ Nessa abordagem, a Teoria de Conjuntos ocupou um lugar privilegiado como base da matemática: "(...) dizemos hoje que é possível, logicamente falando, derivar toda matemática atual a partir de uma origem única: a Teoria dos Conjuntos" ${ }^{44} 0$ grupo referia-se às versões axiomáticas da Teoria dos Conjuntos desenvolvidas após a percepção de paradoxos na proposta de Cantor. ${ }^{45}$ No Brasil, importantes nomes da Educação Matemática, como Benedito Castrucci, fizeram eco a Borbaki:

É uma teoria unificadora na linguagem e na matemática. É o que se observa na notável obra do grupo que trabalha sobre o pseudônimo de Nicolas Bourbaki, a qual começa precisamente pela Teoria dos Conjuntos, em seu Livro I. Diante da orientação moderna do ensino, que tem como objetivo mostrar a unidade da Matemática, o estudo da Teoria dos Conjuntos e o das Estruturas são relevantes e devem estar em primeira plana. ${ }^{46}$ 
A questão do paradoxo não chegou a ser ignorada na Matemática Moderna praticada no Brasil, mas também não mereceu mais do que algumas linhas de referência. Castrucci, não menciona tipos, mas atribui o fim dos paradoxos ao conceito de conjunto universal:

Para evitar o aparecimento de paradoxos, admitimos a existência de um conjunto a qual pertencem todos os elementos com os quais estamos trabalhando. Êste conjunto é denominado conjunto-universo, e salvo casos específicos, será indicado por U. Êste conjunto aparece espontaneamente quando estamos num ramo de Matemática. Assim, se estudamos Geometria Plana, o conjunto-universo é o conjunto de pontos de um plano; se pesquisamos máximo divisor comum e mínimo múltiplo comum, o conjunto é, em geral, o dos números naturais. ${ }^{47}$

Driblando os tipos, que exigiriam uma disciplina adicional no conceito de pertinência, a adoção de um conjunto universo deixaria de fora as coleções muito grandes, como $\{X \mid X \notin X\}$, restringindo 0 escopo de estudos à parte considerada "segura" da teoria e resguardando uma certa aderência à intuição: "A noção intuitiva de conjunto é provàvelmente tão intuitiva quanto a de número. É fácil ver que a criança, quando se refere ao número três, ao mesmo tempo, associa esta idéia a uma coleção de três objetos". ${ }^{48}$

Por esses exemplos, vemos que o conceito de tipos se estabelece (ou não) na matemática conforme a sua conveniência ao uso pretendido em cada situação. Isto reforça a necessidade de observarmos as matemáticas dos mundos, afastando-nos da imposição de uma matemática hegemônica, que se pretenda neutra e universal.

Silva ${ }^{49}$ observou em um coletivo de negros descendentes de escravos no Brasil uma certa dificuldade em contar segundo as normas legitimadas pela matemática escolar. Ele relata: "Se eles têm várias coisas iguais, por exemplo, várias bananas e uma laranja, eles contam como se tivessem só duas unidades, porque as bananas, por serem iguais, contam como uma coisa só". A matemática escolar estabelece a contagem objeto a objeto, mas o olhar matemático daquele grupo, sustentado sobre uma outra rede de exigências, enxergou tipos. Silva insiste na verdade sustentada sob o ponto de vista da matemática escolar, e busca compreender as dificuldades daquele coletivo em aceitar o que para ele é óbvio: "Não adianta tentar ensinar que ali existem dez coisas, sem levar em conta essa cultura anterior". A cultura local é reconhecida, e ocupa um lugar subalterno, uma via de tradução através da qual é imposta a cultura hegemônica. Havia ali duas coisas, bananas e laranjas, mas no artigo da Scientific American prevaleceu a verdade legitimada pela academia: ali existem dez coisas.

As matemáticas não são definitivas. Elas dependem dos mundos e dos propósitos para quais são concebidas.

\section{Matemática}

Pedro Pellegrino, 1982

Um, dois, três

Um mais dois mais três é igual a seis.

Vamos aprender matemática,

MATEMÁTICA:

Observem a palavra,

Contem em si seu segredo

Vamos decompô-la:

MATE M ÁTICA

Primeira filosofia: é preciso matar ATICA

Sabem vocês que TICA é menina em espanhol

E que A é partícula de negação

Logo, derivando deste termo podemos dizer:

Aprender matemática é se libertar de tudo que nega a infância em nós

Nossa homenagem ao poeta Pedro Pellegrino 


\section{Notas e referências bibliográficas}

Isabel Cafezeiro é professora do Instituto de Computação da Universidade Federal Fluminense. E-mail: isabel@dcc.ic.uff.br

Ricardo Kubrusly é professor do Programa de Pós-Graduação em História das Ciências das Técnicas e Epistemologia (HCTE) da Universidade Federal do Rio de Janeiro. E-mail: risk@im.ufr..br

Edwaldo Cafezeiro é professor titular emérito da Faculdade de Letras da Universidade Federal do Rio de Janeiro.

1 Desta citação, omitimos a palavra "diferentes" para fugir da dicotomia que pode transparecer ao relacionar os pares de modalidades enumerados por Darcy Ribeiro. Ao final da primeira seção propomos: "balé, samba, feijoada, xadrez".

2 SARAMAGO, J. Memorial do Convento. Bertrand Brasil, Rio de Janeiro, 1999, p. 63.

3 BENVENISTE, E. O homem na Linguagem. Lisboa, Editora Veja Ltda.,1992.

4 CAfEZEIRO, E. Discurso e Texto. Dimensão Simbólica e Cidadã do Português Brasileiro e Africano. Rio de Janeiro: Editora Achiamé, 2011, p.15.

5 BARRETO, L. O Triste Fim de Policarpo Quaresma. Ministério da Cultura, Fundação Biblioteca Nacional do Livro. Versão para ebook por eBookCult.com.br, seção IV, disponível em http://www.ebooksbrasil.org/adobeebook/policarpoE.pdf.

6 CAFEZEIRO, op. cit., 2011, p.72.

7 Paráfrase de "Nem tupi, nem português, nem negro. Mas português, tupi e negro". CAFEZEIRO, E., ibidem, p.157

8 Fuloresta do Samba é uma banda criada por Siba de Oliveira, na zona da mata pernambucana, uma região castigada pela monocultura da cana de açúcar. A música Toda vez que eu dou um passo o mundo sai do lugar faz parte do CD de mesmo nome e pode ser ouvida em https://soundcloud.com/ search?q=Siba\%20e\%20a\%20fuloresta\%20\%20toda\%20vez\%20que\%20eu\%20dou\%20um

9 DELEUZE, G.; GUATTARI, F. Mil Platôs: Capitalismo e esquizofrenia, vol 1. São Paulo: Editora 34, 1995, p.23.

10 CORALINA, C. Sinos de Goiás. In: Prosas Urbanas. Antologia de Crônicas e Contos para Jovens. São Paulo: Global, 2010, p. 28-32.

11 FREIRE, P. ; BETTO, F. Essa escola chamada vida, depoimentos ao repórter Ricardo Kotscho. São Paulo: Editora Ática, 1985, p15.

12 Consultado em junho de 2015 no sítio: http://www.anosdourados.blog.br/2010/06/imagens-escola-cartilha-sodre_15.html

13 Adaptado do relato oral de Maria Roza Franca Leite à sua neta Isabel Cafezeiro.

14 FREIRE, P. Conscientização e Alfabetização, uma nova visão do processo. Recife: Serviço de Extensão Cultural, Universidade do Recife, 1963.

15 GADOTTI, M. A voz do biógrafo brasileiro: a prática à altura do sonho. Publicação do Instituto Paulo Freire, sem data. Acesso em junho de 2015, no sítio http://siteantigo.paulofreire.org/Crpf/VidaPFBiografias

16 FREIRE, P. Os termos assinalados por nós em itálico problematizam a concepção "exata" da matemática (ou das ciências "exatas"). 0 "rigor" da matemática é uma sugestão. 0 conhecimento matemático não é um saber puro. É, como qualquer outro, um híbrido. Assim "rigor" não é uma característica inerente às entidades matemáticas. Compilado de falas de Paulo Freire enquanto Secretário de Educação, entre 1:10:00 e 1:16:00. Consultado em junho de 2015 no sítio: https://www.youtube.com/watch?v=YcS9IW2Jqow.

17 ENSTEIN, A. Geometry and Experience, 1921. Consultado em junho de 2015 no sítio http://www.relativitybook.com/resources/Einstein_geometry.html

18 BOYER, C. B. História da Matemática. São Paulo: Editora Edgadr Blücher LTDA,1991.

19 FREIRE, P., Entrevistado por Ubiratan d'Ambrosio na seção de abertura do 8th International Congress on Mathematics Education (ICME), Sevilha, 1996. Há uma transcrição da entrevista traduzida para o inglês em FREIRE, P.; D'Ambrosio, U.; Mendonça, M. C. A Conversation with Paulo Freire. For the Learning of Mathematics, v. 17, n. 3, p. 7-10.

20 JAMES, W. The Meaning of Truth. A Sequel to 'Pragmatism'. Adelaide: The University of Adelaide Library, 2014. Consultado em outubro de 2011 no sítio: http://ebooks.adelaide.edu.au/j/james/william/meaning/.

21 CARRAHER, T. N.; CARRAHER, D. W. e SCHLIEMANN, A. D. Na vida dez; na escola zero: os contextos culturais da aprendizagem da matemática. Cad. Pesqui, n.42, 1982, p. 79-86.

22 FLECK, L., Gênese e Desenvolvimento de um Fato Científico. Belo Horizonte: Fabrefactum, 2010, p. 78.

23 FREIRE, P. Extensão ou Comunicação? . São Paulo: Editora Paz e Terra, 2a edição, 1974, p.41.

24 PORTER, T. M. Trust in numbers: the pursuit of objectivity in science and public life. Princeton: Princeton University Press, 1995.

25 FOUCAULT, M. Mal faire, dire vrai. Entrevista concedida à André Berten, trecho 3:00, Bélgica, Universidade Católica de Louvain, 1981. Consultado em junho de 2015 no sítio: https://www.youtube.com/watch?v=rm5WPK- mTI

26 Sobre o termo dispositivo: "em primeiro lugar, um conjunto decididamente heterogêneo que engloba discursos, instituições, organizações arquitetônicas, decisões regulamentares, leis, medidas administrativas, enunciados científicos, proposições filosóficas, morais, filantrópicas. Em suma, 0 dito e o não dito são os elementos do dispositivo. 0 dispositivo é a rede que se pode estabelecer entre estes elementos". Cf. FOUCAULT, M. Microfísica do Poder. Rio de Janeiro: Editora Graal, 2013, p.365. Assim, chamamos de dispositivo da matemática a rede heterogênea de relações onde se articulam poder, saber e efeitos de verdade, e permite compreender a matemática como um campo de saber que se reconhece como articulador da verdade.

27 FOUCAULT, M., op. cit., 1981, trecho 11:19. Consultado em junho de 2015 no sítio: https://www.youtube.com/watch?v=rm5WPK-_mTI

28 CANTOR, G, On an Elementary Question in the Theory of Manifolds. In: EWALD, W. B., editor. From Kant to Hilbert. Oxford: Oxford University Press, 2005.

29 FOUCAULT, M. Outros Espaços. In: Ditos e Escritos III. Estética: literatura e pintura, música e cinema. . 2ª Ed. Rio de Janeiro: Forense Universitária, 2006, p. 414.

30 GÖDEL, K. Über formal unentscheidbare sätze der Principia Mathematica und verwandter systeme. I, Monatsch. Math. Phys., v. 38, p.173-178, 1931. Tradução para o inglês em http://www.research.ibm.com/people/h/hirzel/papers/canon00-goedel.pdf. Acesso em junho de 2015. 
33 TURING, A. On computable numbers, with an application to the Entscheidungsproblem. Proceedings of the London Mathematical Society, Series 2, n.42, 1936, p. 230-265.

34 FOUCAULT, M. História da Loucura na Idade Clássica. São Paulo: Editora Perspectiva, 1978, p. 26.

35 Sobre os paradoxos, e em particular, sobre aqueles paradoxos envolvendo a Teoria dos Conjuntos, H. B. Enderton comenta que, embora o paradoxo de Russell tenha causado um tremendo impacto nas questões dos fundamentos da matemática, ele não foi o primeiro paradoxo percebido na Teoria dos Conjuntos. Cantor já havia notado que a "coleção de todos os conjuntos" deveria ser tratada como uma "totalidade inconsistente", e daí ele sugeriu a distinção entre classes e conjuntos. Ainda anterior à expressão de Russell sobre o paradoxo, Burali-Forti enunciou em "Una questione sui numeri transfiniti." Rendiconti del Circolo Mat. di Palermo 11, 154-164, 1897, uma inconsistência na concepção de existência de um ordinal maior do que todos os outros. 0 conceito de ordinal fora proposto por Cantor para considerar o conceito de ordem abrigando conjuntos infinitos. Cf. Enderton, H. B. Elements of Set Theory. San Diego: Academic Press, 1977, p. 15.

36 RUSSELL, B. The Principles of Mathematics. Apêndice B. Cambridge: Cambridge University Press, 1903. Disponível também no sítio: http://fair-use.org/ bertrand-russell/the-principles-of-mathematics/index.

37 TURING, A. Systems of Logic Based on Ordinals. PhD thesis. Princeton University, 1938.

38 FREIRE, P., op. cit., 1996. Neste trecho, Freire reafirma o que já havia argumentado em sua Pedagogia do Oprimido. Cf. FREIRE, P. Pedagogia do Oprimido. $23^{a}$ edição. Rio de Janeiro: Editora Paz e Terra, 1987, p. 42.

39 ROSA, Noel. Tipo 0. Album Noel. Pela primeira vez cantado por Marília Batista. Consultado em junho de 2015. https://www.youtube.com/ watch? $=1 \mathrm{Hmh} 5 \mathrm{pHZdLs} \# \mathrm{t}=14$

40 Embora a Linguagem tenha sido disponibilizada em 1957, o primeiro manual foi publicado pela Divisão de Pesquisa da IBM em 1956.0 manual está disponível no sítio http://bitsavers.informatik.uni-stuttgart.de/pdf/ibm/704/704_FortranProgRefMan_Oct56.pdf.

41 Existem diversas linguagens que são consideradas sem tipos (typeless). No entanto essa terminologia não significa que a linguagem não adote tipos no sentido amplo que estamos considerando aqui neste artigo, mas que os diferentes conjuntos de valores que a linguagem é capaz de manipular não são identificados pela declaração de cada variável que guarda o valor.

420 breve relato que fazemos neste texto sobre a educação matemática tem como fonte bibliográfica principal a dissertação de mestrado de Flávia Soares intitulada "Movimento da Matemática Moderna no Brasil, avanço ou retrocesso?", e o artigo da mesma autora "Os Congressos de Ensino da Matemática no Brasil nas décadas de 1950 e 1960 e as discussões sobre a Matemática Moderna". Nestes trabalhos, Flávia Soares comenta importantes iniciativas de discussões sobre a matemática que precederam o Movimento da Matemática Moderna no Brasil. Entre elas, a criação do grupo GEEM (Grupo de Estudos do Ensino da Matemática), em São Paulo, e a organização dos Congressos Nacionais do Ensino da Matemática realizados entre 1955 e 1966. Cf. Soares, F. Movimento da Matemática Moderna no Brasil, avanço ou retrocesso?. Dissertação de mestrado. PUC-Rio, 2001. Soares, F. "Os Congressos de Ensino da Matemática no Brasil nas décadas de 1950 e 1960 e as discussões sobre a Matemática Moderna". In: Anais do 10 Seminário Paulista de História e Educação Matemática. São Paulo: IME - USP, 2005. p. 445-452.

43 Cf. BOURBAKI, N. Éléments de Mathematique, Théorie des Ensembles, chapitres 1 à 4. Berlin, Heidelberg, New York: Springer, 1998. Frase introdutória.

44 BOURBAKI, N. op. cit., 1998. 0 trecho citado encontra-se na página 9 da introdução.

45 Já citamos neste texto a proposta de Bertrand Russell para livrar a Teoria dos Conjuntos (TC) dos paradoxos através da adoção de tipos. Outras propostas surgiram na mesma época. É bem conhecida a abordagem de Zermelo Frankael, que distingue conjuntos e classes e introduz a ideia de conjunto universal. Marcelo Coniglio, explica: "A primeira axiomatização de TC foi dada por Zermelo em 1908, e modificada por Fraenkel em 1922, dando origem ao sistema Zermelo-Fraenkel (ZF). Existem muitos outros sistemas, como o de von Neumann-Gödel-Bernays (NGB) e o de Kelley-Morse (KM). Estes últimos usam classes juntamente com conjuntos. Uma classe pode ser pensada como uma coleção 'enorme', de maneira que os conjuntos viriam ser classes 'pequenas'. Por exemplo, $V=\{x: x=x\}$ é a coleção de todos os conjuntos, chamada de classe universal. V é uma classe própria, isto é, ela não é um conjunto, portanto não aparece em nenhum nível da hierarquia cumulativa. Se todos os membros de uma classe aparecem antes de um dado nível, então a classe é um conjunto nesse nível". A hierarquia cumulativa é o artifício para evitar a auto-referência em que se expressam os paradoxos. Aqui, como em Russell, está presente a separação em tipos: "Nível 0: alguns indivíduos. Nível 1: todas as coleções formadas por indivíduos. Nível 2: todas as coleções formadas por elementos no nível 0 ou 1. Em cada nível, considerar as coleções cujos elementos estão em níveis anteriores". Cf. Coniglio, M. Teoria axiomática dos conjuntos. Notas de aula. Disponíveis no sítio: http://www.cle.unicamp.br/prof/coniglio/CONJUN.pdf .

46 CASTRUCCI, B. Elementos de Teoria dos Conjuntos. Série Professor, n. 3, 10ª edição. São Paulo: Livraria Nobel S.A., 1981. Trecho na página 1, na grafia da época. Grifos dos autores. A primeira edição deste livro é da década de 1960.

47 CASTRUCCI, op. cit, 1981, p. 24. Grifos do autor.

48 CASTRUCCI, op. cit, 1981, p. 1. Grifos do autor.

49 Cf. Scientific American Brasil, Etnomatemática, Edição especial, n. 11, 2001, prefácio. COSTA, W. e SILVA, V. L. Matemática Mítica-Religiosa-Corporal do Negro Brasileiro. Scientific American Brasil, Etnomatemática, Edição especial, n. 11, 2001, p. 94.

[Recebido em Julho de 2015. Aprovado para publicação em Maio de 2016] 